\title{
Ion-Molecule Equilibria, How and Why
}

\author{
Paul Kebarle \\ Chemistry Department, University of Alberta, Edmonton, Alberta, Canada \\ (J Am Soc Mass Spectrom 1992, 3, 1-9)
}

$\mathrm{T}$ This article describes how the occurrence of ion-molecule equilibria under thermal conditions was discovered when experiments at high, near-atmospheric, ion source pressures were undertaken for a totally different purpose. It also describes how the instrumentation for the determination of ion-molecule equilibria was developed, and how the field grew so as to provide a vast amount of data on ion-molecule energetics which find application in a number of fields.

Results from ionic equilibria measurements in solution, compiled in the form of acid-base dissociation constants, stability constants for ion-ligand complexes, and electrochemical reduction potentials, represent the quantitative backbone of chemistry in solution. The measurement and recording of such data began in the early 1900s and at the present time this material is a major part of first-year college chemistry.

The same type of basic chemical reactions-proton transfer, ion-ligand association, and electron transfer -occur also in the gas phase. Therefore, valuable information was potentially available from the measurement of ion-molecule equilibria in the gas phase. The instrument with which to observe such reactions was obviously the mass spectrometer. However, when the research to be described started, there was among mass spectrometry researchers little, if any, awareness of this extraordinary opportunity. In the gas phase, at the low pressures of the then available mass spectrometers, ions become discharged on collision with the wall of the apparatus, and therefore the time required for the achievement of an ion-molecule reaction equilibrium is generally not available. Furthermore, the presence of space charge or imposed electric fields does not lead to thermal, MaxwellBoltzmann distribution ions. The thermal conditions required for meaningful equilibria measurements are just not "natural" for this medium. Considering all this, one is not surprised that no mass spectrometry researcher had set about deliberately to develop apparatus for ion-molecule equilibria measurements. It is also not surprising that the discovery that this is possible was with apparatus that was radically different, but designed with other objectives in mind.

The thermochemical data resulting from ion-

Address reprint requests to Paul Kebarle, Chemistry Department, University of Alberta, Edmonton, Alberta, Canada T6G $2 G 2$. molecule equilibria measurements find application in many areas. To give one example: ion-molecule reactions in solution represent the largest class of reactions in organic and inorganic chemistry. The solvent plays an essential role in these reactions, yet solvent effects were poorly understood and therefore often ignored. Thermochemical data for the same reactions occurring in the absence of a solvent, i.e., in the gas phase, provide essential information from which the solvent effect can be deduced.

The ion-molecule equilibria data are also of importance to analytical mass spectrometry. The information on energy changes, relevant to the first great era of analytical mass spectrometry-electron ionization (EI) at low source pressures-came from determinations of ionization energies of molecules and appearance energies of fragment ions. Typically, this involved measurements of ion currents near the energy threshold for the given process [1]. Work in this field, which in its modern applications has become more and more sophisticated [2-4], is still of great importance.

From 1965 onwards, analytical mass spectrometry has experienced wave upon wave of innovations in ionization methods. The first of these was chemical ionization (CI) [5] and this was followed by other methods up to the presently much used plasma desorption [6], secondary ions mass spectrometry [7], fast atom bombardment (FAB) [8], and the new wonder, electrospray [9].

The modern analytical techniques are driven by the task to produce gas-phase ions from nonvolatile, polar, thermally not very stable analytes of biological significance, and this task necessitates the ionization of the analyte in a condensed phase and the "transfer" of the ions to the dilute gas phase. Invariably, this process introduces interactions of the ions with other molecules, i.e., it leads to ion-molecule interactions. Many of the observed ions can therefore be explained on the basis of ion stability information obtained from ion-molecule energetics.

\section{Discovery of Ion-Molecule Equilibria and Development of Instrumentation}

As a new staff member at the Chemistry Department at the University of Alberta, after having done postdoctoral work with Fred Lossing at the Canadian 
Research Council, I was doing research in mass spectrometry. The apparatus was a $90^{\circ}$ magnetic sector, essentially a clone of the instrument that Fred was using, which was home-built, i.e., in part by the National Research Council (NRC) machine shop, in part by ours, with much help and advice from Fred. The research was also very much a line of Fred's research: production of free radicals by photolysis of compounds in a flow system that leaked some of the gas to the mass spectrometer. The radicals could then be detected after electron ionization.

In 1960. Nata Godbole, who had come from India to do postdoctoral work in radiation chemistry with another staff member, asked me whether he could join my laboratory. In casual encounters in the halls of the building, I had been telling him that the mass spectrometer should actually be the most suitable instrument for "serious" research in gas-phase radiation chemistry, and it seems that I had converted him without having intended to do so. After all, I was not a radiation chemist.

Radiation chemistry was an important research area in the years after World War II, in that the effects of ionizing radiation were very much brought to the fore by the development of nuclear weapons. The ionic part of the reactions induced by ionizing radiation obviously was amenable to mass spectrometric investigation. Actually, a number of present-day mass spectrometrists came to the mass spectrometry field via radiation chemistry: Fred Lampe, Jerry Meisels, Jean Futrell, Pierre Ausloos, Sharon Lias, and Michael Henchman, to mention a few that I know.

Ion-molecule reaction studies with conventional, low ion source pressure mass spectrometers had been initiated by Talroze and Lubimova [10], Stevenson and Schissler [11], and Field et al. [12] largely as a response to the interest in radiation chemistry. For a complete historical account, see Lias and Ausloos [13].

Many of these workers and others were gradually inching their way up the ion source pressure ladder from $10^{-5}$ torr upwards, while making small modifications to low pressure mass spectrometers. Because conventional radiation chemistry studies of gases were mostly performed at atmospheric pressure and because the phenomena at such "high" pressures were expected to be quite different [14], Godbole and I decided to make a leap into mass spectrometry at atmospheric pressures.

Three modifications that were required were obvious: reduce the ion source exit slit area to reduce gas outflow, increase the pumping speed in the vacuum region outside the ion source, and increase the penetrating power of the ionizing medium. The first two changes were the standard ones made earlier [10-12], but not radically enough. By placing the ion source inside a 6-in. pumping lead to a 6-in. pumping system, we obtained speeds of $500 \mathrm{~L} / \mathrm{s}$ outside the ion source, which was "very high" by the standards of the time. As penetrating ionizing medium we chose a radioactive polonium-210 $\alpha$-particle source, which was mounted in the ion source $[15,16]$ (Figure 1). The mass analyzer was the $90^{\circ}$ magnetic sector that I had used for the free radical work.

By the time the instrument was complete, Nata Godbole had left to take a permanent position and Alan Hogg, my first graduate student, had joined the mass spectrometry research. Alan today is known to many as the director of the excellent Departmental Analytical Mass Spectrometry facility at the University of Alberta.

The mass spectra observed with the new apparatus, when gases at near-atmospheric pressure were introduced into the ion source, proved to be very bewildering. Most often the ions observed bore no relation to the gas introduced. This was particularly the case when the gas was "inert," such as $\mathrm{N}_{2}$ or one of the noble gases. We had stepped far out and were

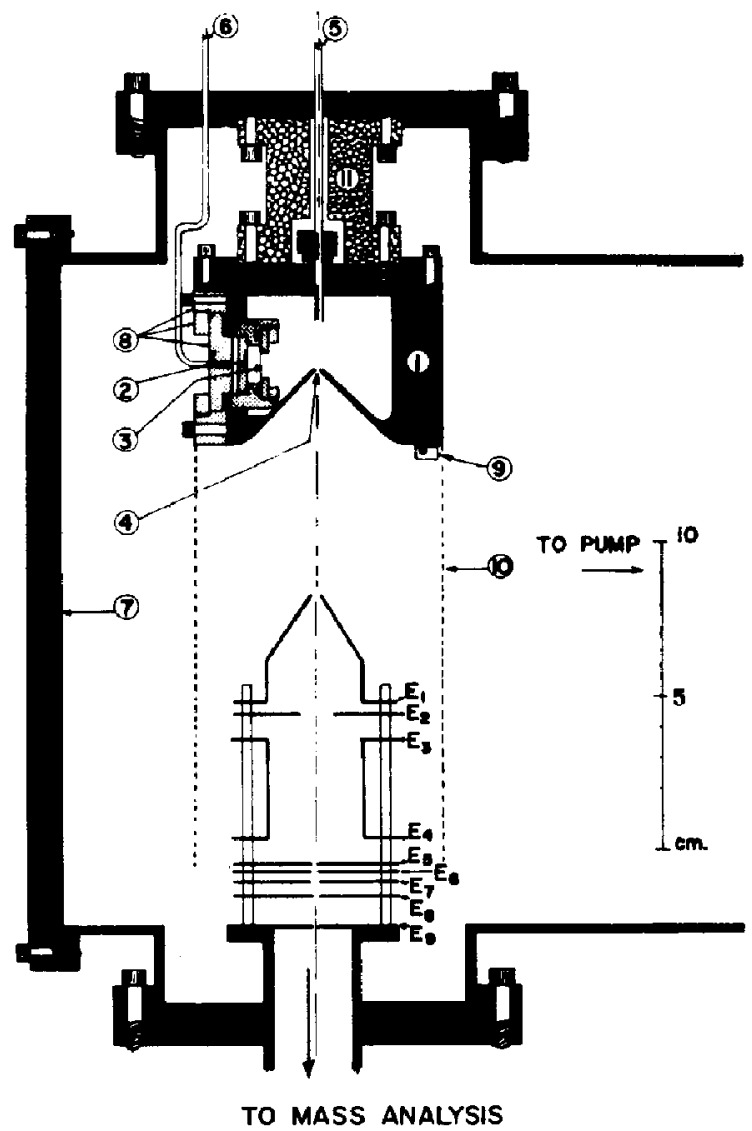

Figure 1. Ion source of first atmospheric pressure instrument: (1) stainless ion source; (2) aluminium disk with ${ }^{210} \mathrm{P}_{0}$ activity (blackened area); (3) nickel window; (4) pinhole in tantalum foil; (5) gas supply line; (6) $\alpha$-compartment pressure equalization; (7) side entrance; (8) stainless $\alpha$-source container; (9) auxiliary flament. (Reprinted with permission from Kebarle, P.; Hogg A. M. I. Chemt. Phys. 1965, 42, 668. American Institute of Physics.) 
totally unfamiliar with the new conditions, so it took some time before we realized that the ions that we were seeing were due to trace impurities which reacted with and removed the primary ions formed from the major gas. With reactive gases such as ethylene, a forest of peaks extending well beyond $m / z 200$ was observed [16]. The complex ethylene spectra could not be explained beyond the obvious fact that some sort of polymerization by ion-molecule reactions was occurring.

In the search for simpler conditions we used an inert major gas like $\mathrm{Xe}$ and added traces of the reactive gas ethylene. The observed ethylene-derived ions now did include products of ion-molecule reactions that had been observed at low ethylene pressures [16]. The conditions and observations in these experiments were similar to the CI conditions developed independently and so ably exploited for analytical purposes just a few years later by Munson and Field [17]. We had noticed the high sensitivity under our atmospheric pressure ionization (API) conditions for ionization of trace gases [16] but did not grasp the analytical potential that was realized in CI by Munson and Field and much later in API by Horning et al. [18].

Fortunately, we did not miss every opportunity. In many gases such as "laboratory air," we noticed series of peaks spaced at 18 mass units apart, which we soon identified as the $\mathrm{H}_{3} \mathrm{O}^{+}\left(\mathrm{H}_{2} \mathrm{O}\right)_{n}$ clusters [15, 16]. Significantly, the intensities of these peaks did not extend in an irregular pattern, as was the case for ethylene, but formed rice, bell-shaped distributiors when unknown impurity ions did not interfere. The least interference from impurities was observed with ammonia gas. The observed distribution of the $\mathrm{NH}_{4}^{+}\left(\mathrm{NH}_{3}\right)_{n}$ clusters is shown in Figure 2. The contrast between the intensity distributions observed for ethylene where chemical, valence forces brought about the polymerization, and the ions in Figure 2, where weaker "physical" forces brought about the "polymerization," suggested to us that the observed water and ammonia cluster distributions must be due to the achievement of cluster equilibria in the ion source. As the cluster grew, bonding to the new solvent molecules was expected to decrease because the ion charge promoting the bonding got farther and farther away. This would ultimately lead to fast, reverse declustering reactions and achievement of equilibrium (eq 1):

$$
\mathrm{NH}_{4}^{+}\left(\mathrm{NH}_{3}\right)_{n-1}+\mathrm{NH}_{3} \underset{\mathrm{r}}{\stackrel{\mathrm{f}}{\rightleftharpoons}} \mathrm{NH}_{4}^{+}\left(\mathrm{NH}_{3}\right)_{n}
$$

The mass spectra, shown in Figure 2, illustrate well the problem with impurities encountered in the early work, even for a gas like ammonia, whose high proton affinity should have led to the dominance of $\mathrm{NH}_{4}^{+}$ core ion peaks. One lesson learned was that we must not only have pure gases but also a very clean gas
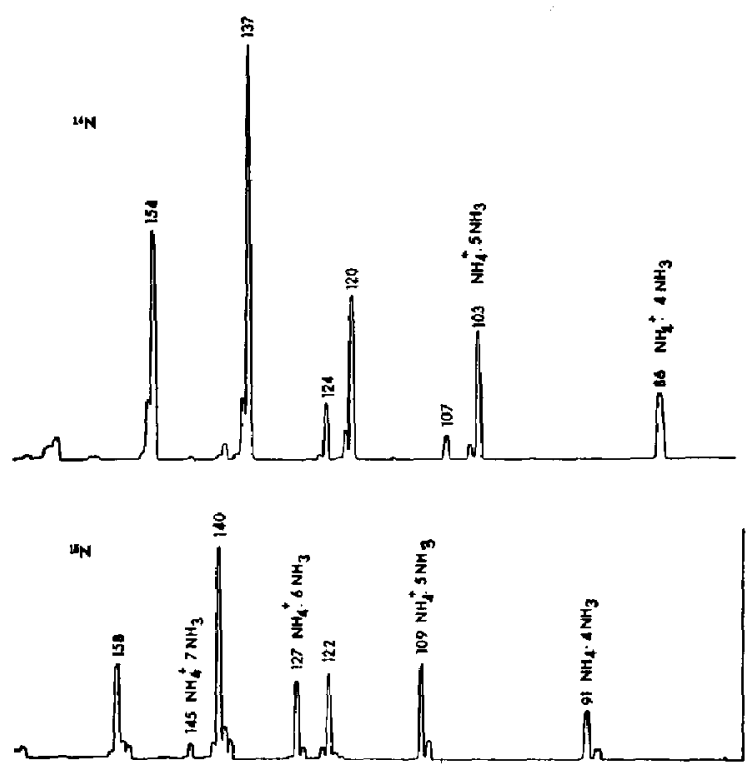

Figure 2. Early results illustrating problems due to trace impu rities. (Top) $\mathrm{NH}_{4}^{+}\left(\mathrm{NH}_{3}\right)_{n}$ ion distributions from ${ }^{14} \mathrm{NH}_{3}$ at 15-torr ion source pressure. Masses 120,137 , and 154 contain $\mathrm{NH}_{4}^{+}$. $\mathrm{nNH}_{3}$ series plus impurity (overlap) series. Masses 104 and 121 are due to $1 \mathrm{~mol}$ of water in solvation shell. The ions of masses 107,124 , and 141 are due to another solvated impurity. (Bottom) Recorder tracing from ${ }^{15} \mathrm{NH}_{3}$ at same conditions shown $\mathrm{NH}_{4}^{+}$. $\mathrm{nNH}_{3}$ series and overlap impurity series (masses 122, 140, 158). (Reprinted with permission from Hogg, A.M.; Kebarle, P. I. Chem. Phys. 1965, 43, 449. American Institute of Physics.)

inlet system. A change to an all-glass and metal-gas handling plant wert a long way to remove many of the impurity problems.

The presence of an equilibrium, such as shown in eq 1 , can be subjected to simple tests. Thus, the equilibrium constant $K$ (see eq 2),

$$
\begin{gathered}
K_{n-1, n}=\frac{\left[\mathrm{NH}_{4}^{+}\left(\mathrm{NH}_{3}\right)_{H}\right]}{\left[\mathrm{NH}_{4}^{+}\left(\mathrm{NH}_{3}\right)_{n-1}\right] \mathrm{P}\left(\mathrm{NH}_{3}\right)} \\
\frac{I_{\mathrm{NH}_{4}^{+}}\left(\mathrm{NH}_{3}\right)_{n}}{I_{\mathrm{NH}_{4}^{+}\left(\mathrm{NH}_{3}\right)_{n-1}}} \approx \frac{\left[\mathrm{NH}_{4}^{+}\left(\mathrm{NH}_{3}\right)_{n}\right]}{\left[\mathrm{NH}_{4}^{+}+\left(\mathrm{NH}_{3}\right)_{n-1}\right]} \\
R T \ln K_{n-1, n}=-\Delta G_{n-1, n}^{\circ} \\
\Delta G_{T}^{\circ}=\Delta H^{\circ}-T \Delta S^{\circ} \\
R \ln K=-\Delta H^{\circ} / T+\Delta S^{\circ}
\end{gathered}
$$

where the ion concentration ratio is replaced by the mass spectrometrically detected ion intensity ratio (see eq 3), should remain invariant when the (ammonia) pressure is changed at constant temperature. Furthermore, measurements of $K$ at different temperatures $T$ 
should lead via van't Hoff plots, i.e., $R \ln K$ vs $1 / T$, to straight lines (see eqs 4-6). The slopes of these lines should then provide the enthalpy change $\Delta H_{n-1, n}^{\circ}$ and the intercept the entropy change, $\Delta S_{n-1, n}^{\circ}$, for the given reaction $(n-1, n)$.

Although the initial tests worked only so-so [19, 20], we had great faith that the equilibria were really occurring and that when we improved the conditions of measurement, we would get better data. We also began to understand why we had hit onto conditions that led to thermal ion-molecule equilibria. The high gas pressures used slowed down very much the diffusion of the ions to the wall. The slow diffusion increased greatly the residence time of the ions in the ion source and allowed the reactive equilibria to occur. In a sense, we had "trapped" the ions in the ion source by the diffusion "barrier" due to the high pressure. The very low intensity and diffuse $\alpha$-particle ionization source led to very low ion concentrations in the ion source such that ion-electron recombination was even slower than the slow ion loss by diffusion to the wall. The very low ion concentrations also led to minimal space charge and thus to thermal, Maxwell-Boltzmann ion distributions in the ion source. The fact that the dominant ion loss mechanism is due to diffusion, and diffusion is first order in the ion concentration, leads also to conditions that are amenable to relatively simple kinetic analysis.

However, the $\alpha$-particle source was a nuisance. The polonium was covered by a mica sheet, and after some time, the mica sheet would crack and polonium would start migrating through the vacuum system. We hated to see, when we vented the vacuum, that the chevron baffle of the liquid nitrogen trap made the Geiger counter go wild. Furthermore, the spreading of the polonium was accelerated at high ion source temperatures, and temperature was a most important variable in our thermodynamic studies. So, Gary Collins, my second doctoral student, and I put together a high pressure mass spectrometer that used a $100-\mathrm{kV}$ proton beam as ionizing medium [21]. The Walton Cockroft proton accelerator came from a secondhand neutron generator for neutron activation analysis which we acquired for Can $\$ 6000$.

This new instrumentation allowed us to do the first extensive study of the important $\mathrm{H}^{+}\left(\mathrm{H}_{2} \mathrm{O}\right)_{H}$ equilibria over a wide temperature range [21]. A summary of the data obtained is shown in Figures 3 and 4. Figure 3 gives the van't Hoff plots obtained for this system. These provided the $\Delta H_{n-1, n}^{\circ}, \Delta G_{n-1, n}^{\circ}$, and $\Delta S_{n-1, n}^{\circ}$ data for $n$ values from 2 to 8 . The thermal equilibrium distributions for the $\mathrm{H}^{+}\left(\mathrm{H}_{2} \mathrm{O}\right)_{n}$ clusters that could be evaluated with these data are shown in Figure 4.

The proton beam instrument had its disadvantages: now there were $x$-rays to guard against. These were produced from secondary electrons being accelerated towards the high positive voltage electrodes.

My third doctoral student, Dave Durden, put to-

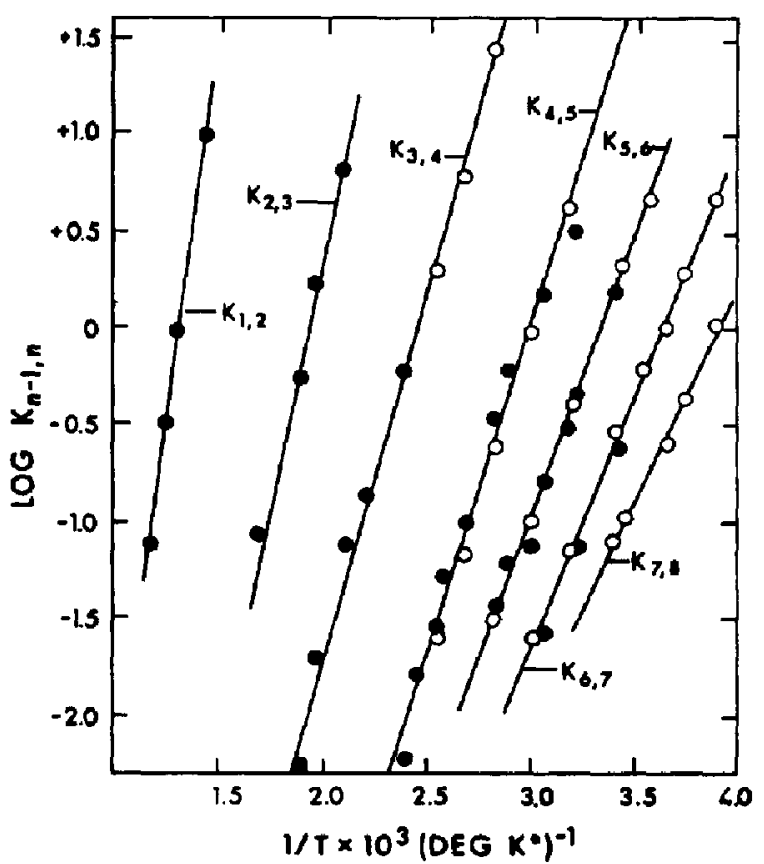

Figure 3. van't Hoff plots for cluster equilibria: $\mathrm{H}^{+}\left(\mathrm{H}_{2} \mathrm{O}\right)_{n-1}$ $+\mathrm{H}_{2} \mathrm{O}=\mathrm{H}^{+}\left(\mathrm{H}_{2} \mathrm{O}\right)_{n}$, measured with $\alpha$-particle mass spectrometer (O) or proton mass spectrometer (-). (Reprinted with permission from the Journal of the American Chemical Society. 1967 American Chemical Society.)

gether a third instrument, which first used $20-\mathrm{kV}$ electrons. These were passed into the ion source through a very thin foil and the foil needed to be supported and cooled by a copper grid to avoid burnout by the beam. The troubles that such arrangements lead to are known only to those who have tried them!

Fortunately, by this time we realized fully that our main purpose was not to solve problems of radiation chemistry at atmospheric pressure but to determine ion-molecule equilibria and that these could be measured with far less trouble at lower pressures, i.e., in the 3-10 torr region. The ionizing electrons needed to be much less penetrating at these pressures and we settled on 2000-V electrons passed through a narrow slit into the ion source. This apparatus $[22,23]$, which used a quadrupole mass analyzer, is shown in Figure 5. The electron beam could be pulsed and this allowed kinetic measurements. So now one could observe not only equilibrium ion ratios but also the kinetics of the approach and achievement of equilibrium (Figure 6).

Pulsing of the electron beam for purposes of measuring the kinetics of ion-molecule reactions had been used earlier at low ion source pressures $p<10^{-1}$ torr by Talroze and Frankevich [24] and Shannon et al. [25]. However, at low pressures the ion residence times in the source, before discharge on the wall, are 

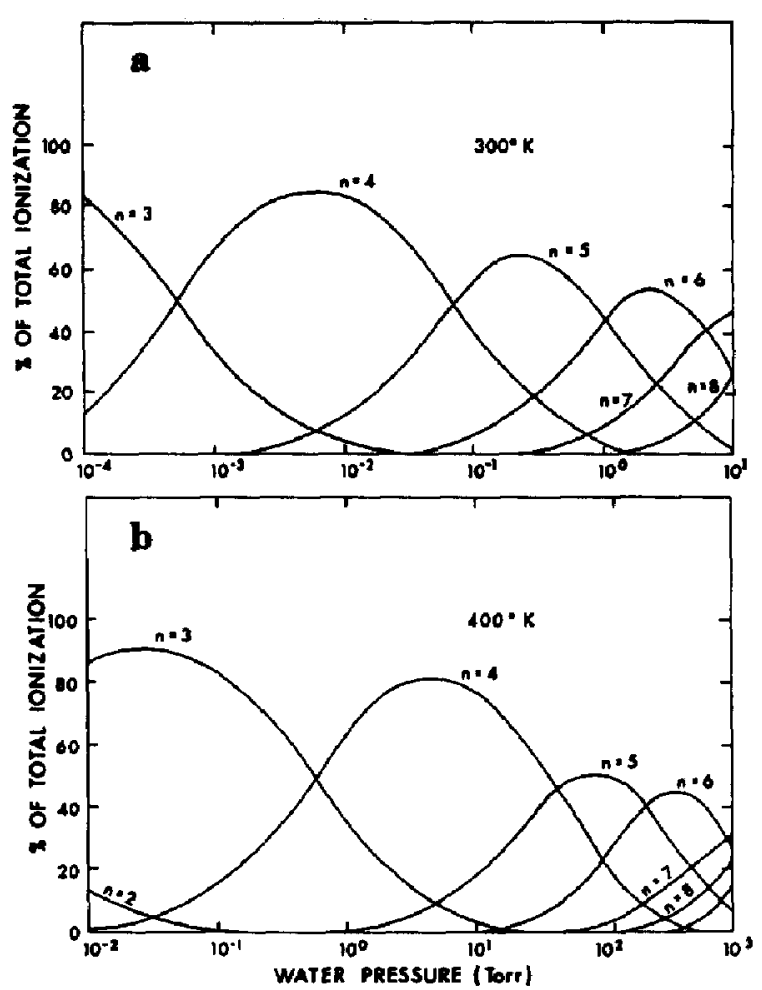

Figure 4. Equilibrium distributions of clusters $\mathrm{H}^{+}\left(\mathrm{H}_{2} \mathrm{O}\right)_{n}$ predicted by experimental data; logarithmic scale used for water partial pressure to accommodate a wide pressure range: (a) $300^{\circ} \mathrm{K}$, (b) $400^{\circ} \mathrm{K}$. (Reprinted with permission from the foumal of the American Chemical Society. 1967 American Chemical Society.)

very short ( $-1 \mu \mathrm{s})$ and rate measurements are very difficult. At pressures in the torr range, the residence times are long $(-100-1000 \mu \mathrm{s})$ and rate measurements for even very slow reactions are easy.

The cross-sectional diagram of the apparatus in Figure 5 is of our first pulsed high pressure mass spectrometer (PHPMS) which included all the essential features present in subsequent equipment [26]. One last refinement was the ion exit slit. To sample the ions from the high pressure source, we needed to maintain molecular flow at the ion exit orifice. But at high pressures even a $100-\mu \mathrm{m}$ diameter orifice leads to rapid expansion, formation of a supersonic molecular beam, and large drop of temperature. Therefore, to maintain molecular flow, we used initially a square array of some 30 small holes, each $5 \mu \mathrm{m}$ in diameter. The holes were produced by a focused laser beam and the metal foil used was $5 \mu \mathrm{m}$ thick. However, these small holes tended to become plugged very easily. An alternative was to use a long and very narrow slit, something like $1000 \times 5 \mu \mathrm{m}$. This slit was developed by Stu Searles, my fourth graduate student and the first originating from the United States. It consisted of two razor blade edges spot welded over a stainless steel plate that had a $1000-\mu \mathrm{m}$ diameter hole. It proved completely successful and is still a "trademark" part in our instrumentation.

Looking back now on this initial period of intense development of instrumentation, it appears to me a heroic and a happy time. I was not much older than my graduate students, and at parties they brought their wives and babies and we brought ours. Joint extracurricular activities, such as canoeing with the group, where one graduate student was often the leader, also were much fun. Figure 7 is a photograph taken in the laboratory at the time.

\section{Major Types of Ion-Molecule Equilibria and Some Applications of the Data}

Ion-molecule equilibria determinations proved to be an extraordinarily prolific source of unique data. Determinations from this laboratory with PHPMS apparatus involved furst only ion-ligand (or solvent) molecule equilibria [26] (see eqs 1-4). However, soon it became clear that many other equilibria can also be measured, such as proton transfer, electron transfer, hydride ion transfer, halide ion transfer, and so on.

Other research groups joined the fleld. High pressure techniques were used by Meot-Ner and coworkers [27], Franklin and co-workers [28], Tang and Castleman [29], Meisels et al. [30], Meot-Ner et al. [31], Jennings and co-workers [32], Stone et al. [33], Hiraoka et al. [34], and McMahon and co-workers [35].

A very important development was the application of ion cyclotron resonance (ICR) to ion equilibria measurements. Mass analysis can be obtained with ICR only at low pressures ( $\mathrm{p} \leq 10^{-6}$ torr), so ion equilibria determinations became possible only after the development of the trapped ion cell; see Mclver et al. [36]. The increased ion residence time, which with present ICR techniques extends into seconds and minutes, allows the determination of transfer equilibria even though the reaction rates are very much slower because of the low reactant gas pressures that have to be used to maintain efficient trapping. Outstanding contributions to the ion equilibria field were made by several groups using the trapped ion ICR and Fourier transform (FT) ICR technique; see Henderson et al. [37], Aue and Bowers [38], Bartmess and co-workers $[39,40]$, and Larson and McMahon [41].

The fast flow techniques, flowing afterglow, and the selected ion flow tube, which are operated at intermediate pressures, are very well suited for kinetic measurements of equilibrium corstants and have led to a large number of determinations; see Dunkin et al. [42], Schiff and co-workers [43], and Adams et al. [44]. 


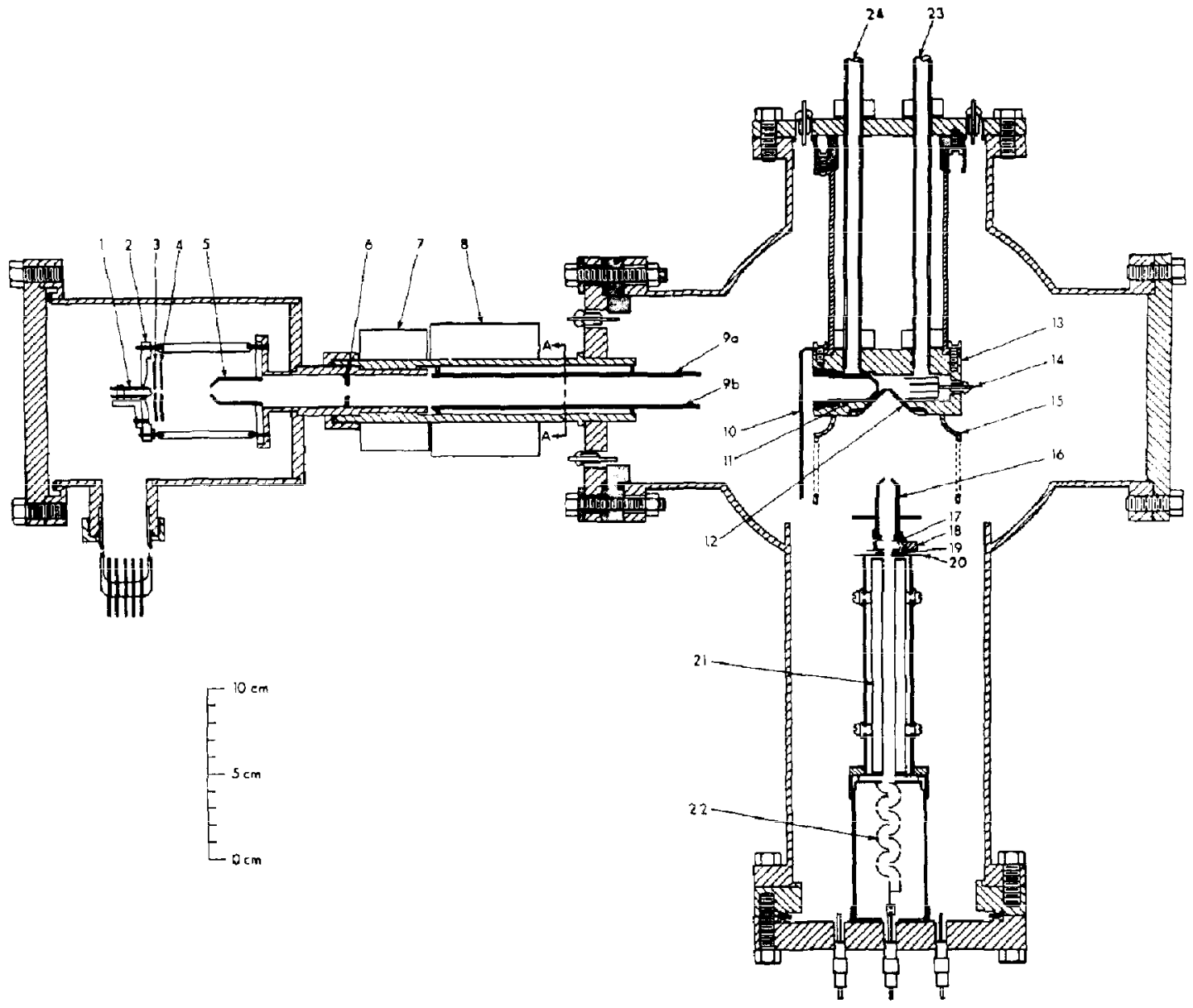

Figure 5. First pulsed electron, high ion source pressure mass spectrometer built by Dave Durden. Electron energies used: $20-2 \mathrm{kV}$; (1) electron flament; (2) electron reflector; (3 and 4) electron extraction electrodes; (5) electron acceleration electrode; (6) collimation electrode; (7) solenoid coil providing axial magnetic freld for electron focusing; (8) T.V. yoke for $x, y$ motion of electron beam; (9a, b) deflection plates for electron pulsing; (10) fluorescent screen; (11) electron entrance port; (12) ion exit cone carrying leak; (13) ion source with heaters; (14) electron trap; (15) shieiding screen; (16-20) ion focusing electrodes; (21) quaurupole mass analyzet; (22) electron multiplier. Ion source $+7 \mathrm{~V}$, electrode 16 at $-90 \mathrm{~V}$, electrodes $17-20$ at ground potential. (Reprinted with permission from Durden, D.; Kebarle, P.; Good, A. J. Chem. Phys, 1969, 50, 805. American Institute of Physics.)

The types of equilibria that have become major sources of data are listed below.

\section{Ion-Ligand, Ion-Solvent Molecule Equilibria}

The equilibria are represented by the general equation (eq 7):

$$
\operatorname{Ion}(L)_{n-1}+L=\operatorname{Ion}(L)_{n}
$$

The ion may be positive $\left(\mathrm{Li}^{+}, \mathrm{Na}^{+}, \mathrm{K}^{+}, \mathrm{Rb}^{+}, \mathrm{Cs}^{+}\right.$, $\mathrm{NH}_{4}^{+}, \mathrm{CH}_{3} \mathrm{NH}_{3}^{+}, \mathrm{H}_{3} \mathrm{O}^{+}, \mathrm{CH}_{3} \mathrm{OH}_{2}^{+}$, etc.) or negative $\left(\mathrm{F}^{-}, \mathrm{Cl}^{-}, \mathrm{Br}^{-}, \mathrm{I}^{-}, \mathrm{NO}_{2}^{-}, \mathrm{NO}_{3}^{-}, \mathrm{HCO}_{2}^{-}, \mathrm{C}_{6} \mathrm{H}_{5} \mathrm{O}^{-}\right.$, etc.). A varicty of ligands $L\left(\mathrm{H}_{2} \mathrm{O}, \mathrm{CH}_{3} \mathrm{OH}, \mathrm{CH}_{3} \mathrm{CN}\right.$,
$\left(\mathrm{CH}_{3}\right)_{2} \mathrm{SO}$, etc.) have been used. For a summary, see Keesee and Castleman [45]. See also the preceding section where some of the early data were presented.

Proton Transfer, Proton Affinity of Neutral Bases, and Acidities of Neutral Acids

Proton transfer involving positive ions provides the relative basicities of neutral bases; see eq 8 :

$$
\begin{aligned}
\mathrm{H}_{3} \mathrm{O}^{+}+\mathrm{CH}_{3} \mathrm{OH} & =\mathrm{H}_{2} \mathrm{O}+\mathrm{CH}_{3} \mathrm{OH}_{2}^{+} \\
A \mathrm{H}^{+}+B & =A+B \mathrm{H}^{+}
\end{aligned}
$$



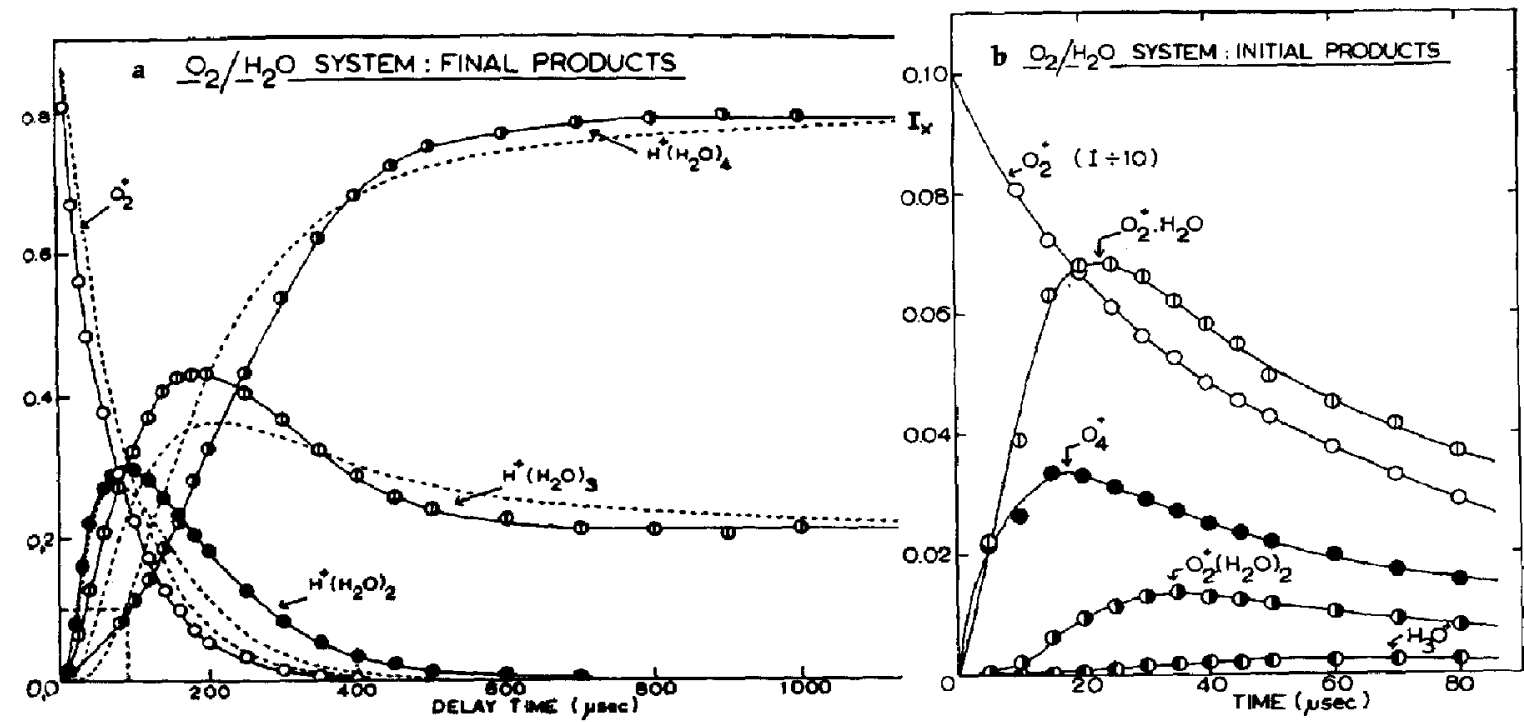

Figure 6. Ion intensity time dependence after short $-10-\mu \mathrm{s}$ electron pulse observed with apparatus shown in Figure 5. Gas $\mathrm{O}_{2}\left(2\right.$ torr) containing 4 mtorr of $\mathrm{H}_{2} \mathrm{O}$, at 307K. (a) Intensities of major ions showing ultimate ions $\mathrm{H}^{+}\left(\mathrm{H}_{2} \mathrm{O}\right)_{4}$ reaching equilibrium. (b) Ionic intermediates showing the conversion of the primary ions $\mathrm{O}_{2}^{+}$to $\mathrm{H}^{+}\left(\mathrm{H}_{2} \mathrm{O}\right)_{n}$ via the complex reaction sequence: $\mathrm{O}_{2}^{+} \rightarrow \mathrm{O}_{4}^{+} \rightarrow \mathrm{O}_{2}^{+} \mathrm{H}_{2} \mathrm{O} \rightleftharpoons \mathrm{O}_{2}^{+}\left(\mathrm{H}_{2} \mathrm{O}\right)_{2} \rightarrow \mathrm{H}_{3} \mathrm{O}^{+}$. Some 14 rate constants, relating to the major reactions, could be obtained. (Reprinted with permission from Good, A.; Durden, D. A.; Kebarle, P. I. Chem. Phys. 1970, 52, 222. American Institute of Physics.)

The relative proton affinities obtained from these equilibria lead to a scale of relative proton affinities. This scale can be made absolute by calibrating it to one absolute proton affinity value determined by some other method [26].

A bird's eye view of the proton affinities is provided by Figure 8 . Very low proton affinities are observed for $\sigma$ electron pair donor bases like $\mathrm{H}_{2}$ and $\mathrm{CH}_{4}$. The proton affinities increase from $\sigma$ to $\pi$ to $n$ electron pair donor bases. However $n$ donor bases with very electronegative atoms like $H F$ also can have very low basicities. The basicities of $n$ donor bases increase in the order, $\mathrm{F}, \mathrm{Cl}, \mathrm{Br}, \mathrm{O}, \mathrm{N}$. One of the strongest organic bases is 1,8-tetramethyldiaminonaphthalene. In this case the high basicity of $N$ bases is combined with additional stabilization due to dicoordination of the proton and release of strain due to methyl group repulsions in the neutral base [46].

Acidities of neutral acids are obtained from proton transfer equilibria involving negative ions, as shown in eq 9.

$$
\begin{aligned}
\mathrm{CH}_{3} \mathrm{CO}_{2}^{-}+\mathrm{CH}_{2} \mathrm{CICO}_{2} \mathrm{H} & =\mathrm{CH}_{3} \mathrm{CO}_{2} \mathrm{H}+\mathrm{CH}_{2} \mathrm{CICO}_{2}^{-} \\
A^{-}+B \mathrm{H} & =A \mathrm{H}+B^{-}
\end{aligned}
$$

An acidity scale giving an overview of change of gas-phase acidity with molecular structure is given in Figure 9.

The proton affinity scale in Figure 8 predicts the order in which analyte compounds will have an in- creasing tendency to form the "quasi molecular ion" $\mathrm{MH}^{+}$in $\mathrm{Cl}, \mathrm{API}, \mathrm{FAB}$, thermospray, and electrospray, whereas Figure 9 provides the relative tendency for formation of the quasimolecular ion $(\mathrm{M}-\mathrm{H})^{-}$ in the negative ion spectra observed with the above techniques.

\section{Electron Transfer}

Measurements of electron transfer equilibria (see eq 10) have proven to be an excellent source of electron affinities of molecules. Within a few years a few

$$
A^{-}+B=A+B^{-}
$$

hundred values have been obtained with this technique $[47,48]$. The scale of electron affinities [48] provides a guide to the tendencies of molecules to form the negative molecular ion $\mathrm{M}^{-}$.

The compilation by Lias et al. [49] is seen to provide 1000 proton affinities and close to 1000 gas-phase acidities and electron affinities and these data are based on ion equilibria measurements.

The intense period of instrumental development in our laboratory, described in the preceding section, gave way to an intense period of measurements leading to some of the data described in the present section. However, the really exciting part was not the production of the data but their application. Each group of measurements, sometimes even just the 


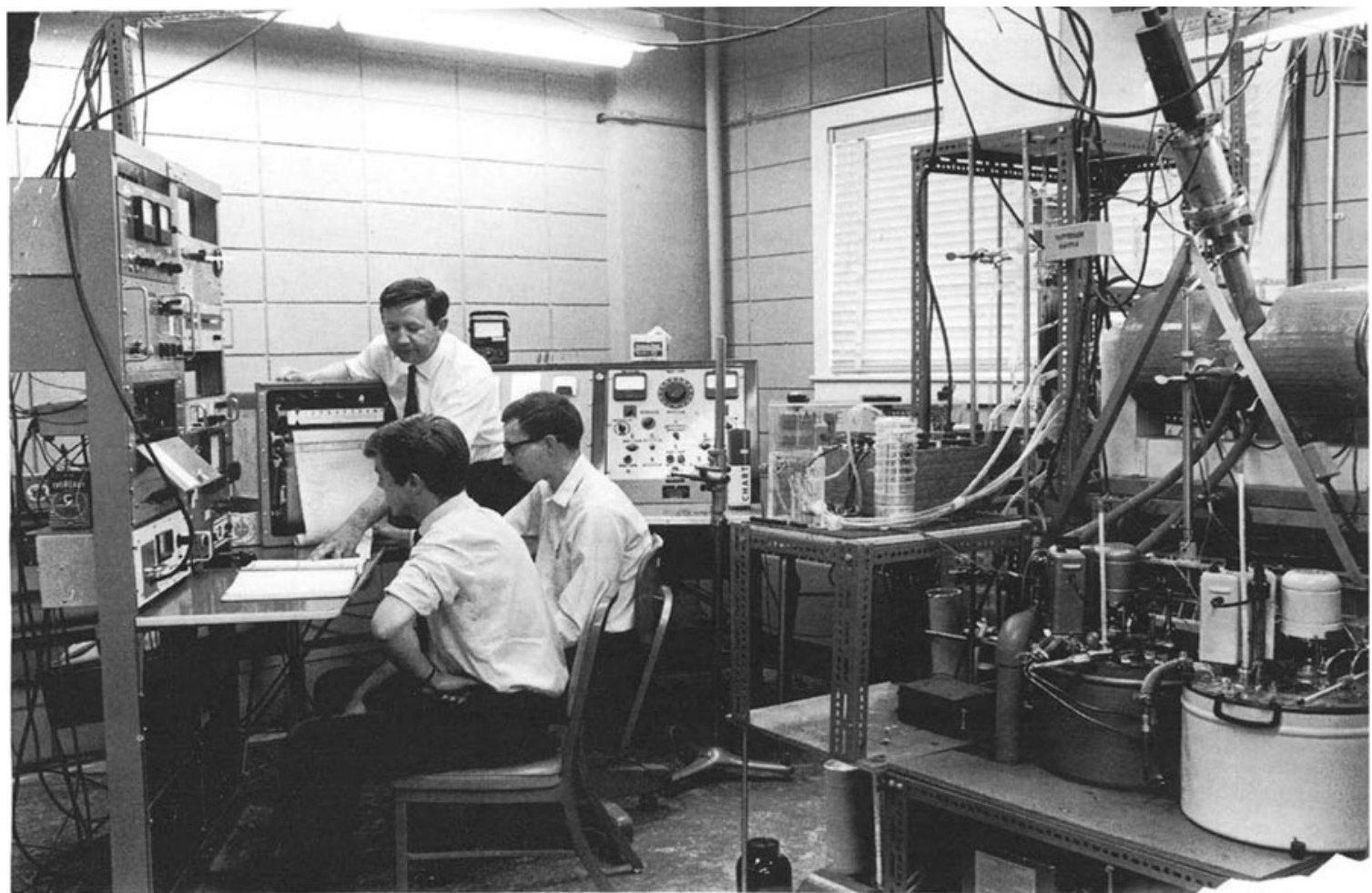

Figure 7. Group photograph of early workers on high pressure mass spectrometry. Standing: the author. Sitting: John Scarborough and Stu Searles. Instrument: proton beam mass spectrometer. Center background: console for 100-kV Walton-Cockroft accelerator.

value for one compound, had an application somewhere, from the ionosphere and gaseous electronics to physical organic and biochemistry. We had to learn a lot of chemistry so as to be able to interact with workers in these diverse fields. In retrospect, this

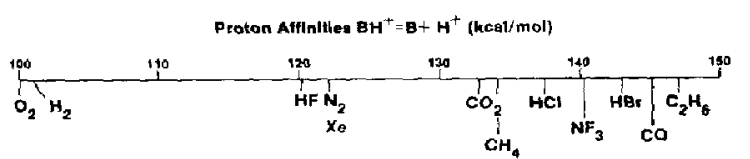

$\underbrace{\mathrm{CH}_{3} \mathrm{C}_{3} \mathrm{H}_{3}}_{\text {COS }}$

$\triangle P_{2}=150$ kcolimal $\triangle P K_{E}=102$

Figure 8. Scale of proton affinities, providing $\Delta H$ for reaction: $B \mathrm{H}^{+}=B+\mathrm{H}^{+}$, based on proton transfer equilibria measurements. interaction was also one of the most interesting and rewarding experiences.

Mass spectrometry is really a method by which data are obtained. It is very demanding and with a vast scope, but this scope is largely in service to other

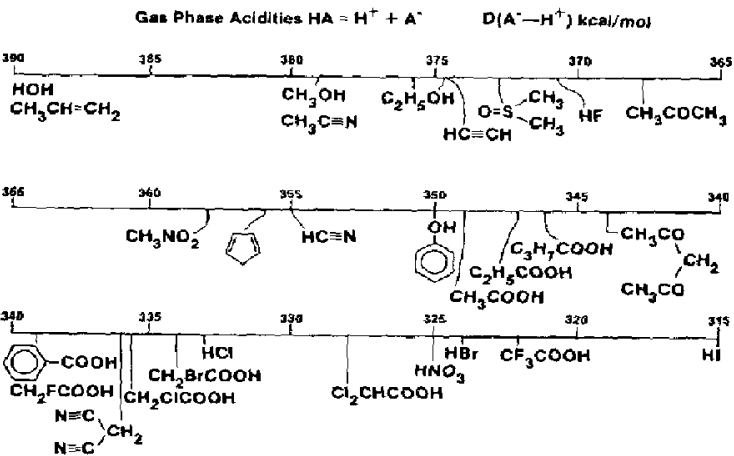

$A$ (Aclouly) * 35 kenumol $48 \mathrm{~kJ}=54$

Figure 9. Scale of gas-phase acidities, giving $\Delta H$ for reaction $A H=A^{-}+\mathrm{H}^{+}$, based on proton transfer equilibria measure ments. 
fields. One way that one can enjoy performing that service is to immerse oneself also in the field or discipline to which the data apply. I think that many mass spectrometrists have found this double challenge to be the most rewarding part of our occupation.

\section{References}

1. Field, F. H.; Franklin, J. L. Electron Impact Phenomena; Academic: New York, 1957. Rosenstoek, H. M.; Draxl, K.; Steiner, B. W.; Herron, J. T. J. Phys. Chem. Ref. Data 1977, 6, Suppl. I.

2. Cooks, R. G.; Kim, K. C.; Beynon, J. H, Chem. Phys. Lett. 1977, 26, 131.

3. Baer, T. In Ionic Processes in the Gas Phase; Almosler-Ferreira, M. A., Ed; NATO ASI Series; D. Reidel, Dordrecht, Netherlands, 1982.

4. Proch, R.; Rider, D. M.; Zare R. N. Cherm. Phys. Lett, 1981 , 81,430 .

5. Field, F. H.; Munson, M. S. B. I. Am. Chem. Soc. 1965, 87, 3289.

6. Torgerson, D. F.; Skowronski, R. P.; Macfarlane, R. D. Biochem. Biophys, Res. Commun, 1974, 60, 616.

7. Bennighoven, A., Ed. Ion Formation from Organic Solids, Springer-Verlag: New York, 1983.

8. Barker, M.; Bordoli, R. S.; Jedgwick, R. D.; Tyler, A. N. $J$. Chem. Soc., Chem. Commun. 1981, 325.

9. Fenn, I. B.; Mann, M.; Meng, C. K.; Wong, S. F. Mass Spectrom. Rev. 1990, 9, 37.

10. Talroze, V. L.; Lubimova, A. K. Dokl. Akad. Nauk USSR $1952,86,909$.

11. Stevenson, D. P.; Schissler, D. O. J. Chem. Phys. 1955, 23, 1353.

12. Field, F H.; Franklin, J. L.; Lampe, F. W. I. Am. Chem. Soc. 1957, 79, 2419.

13. Lias, S. G,; Ausloos P. Ion Molecule Reactions; Research Monographs in Radiation Chemistry; American Chemical Society: Washington, DC, 1975.

14. Kebarle, P.; Godbole, E. W. J. Chem. Phys. 1962, 36, 302.

15. Kebarle, P.; Godbole, E. W. J. Chem. Phys. 1963, 39, 1131.

16. Kebarle, P.; Hogg, A. M. J. Chem. Phys. 1965, 42, 668.

17. Munson, M. S. B.; Field, F. H. J. Am. Chem. Soc. 1966, 88 , 2621.

18. Horning, E. C.; Horning, M. G.; Caroll, D. I.; Dzidic, I.; Stillwell, R. N. Anal. Chem. 1973, 45, 936.

19. Kebarle, P.; Hogg, A. M. J. Chem. Phys, 1965, 42, 798.

20. Hogg, A. M.; Kebarle, P. J. Chem. Phys. 1965, 43, 449.

21. Collins, J. G.; Kebarle, P. J. Chem. Phys. 1967, 46, 1082. Kebarle, P.; Searles, S. K; Zolla, A.; Scarborough, J.; Arshadi, M. J. Am. Chem. Soc. 1967, 89, 6393.

22. Durden, D. A.; Kebarle, P.; Good, A. J. Chem. Phys. 1969, 50, 805.

23. Good, A.; Durden, D. A.; Kebarle, P. I. Chem. Phys. 1970, 52,222

24. Talroze, V. L.; Frankevich, E. L. Zh. Fiz. Khim. 1960, 34, 2709.

25. Shannon, T. W; Meyer, F.; Harrison, A. G. Can. J. Chem. $1965,43,159$.
26. Kebarle, P. In Techniques for the Study of Ion-Molecule Reactions; Farrar, J. M.; Saunders, W., Eds.; John Wiley: New York, 1988. Kebarle, P. Annu. Rev. Phys. Chem. 1977, 28 , 445.

27. Solomon, J. J.; Meot-Ner, M.; Field, F. H. I. Am. Chem. Soc. 1974, 96, 3727. Meot-Ner, M.; Sieck, L. W. J. Am. Chem. Soc. 1983, 105, 2956.

28. Chong, S. L.; Franklin, J. L. J. Chem. Phys. 1971, 54, 1487. Horton, R. L.; Franklin, J. L.; Mazzeo, B. J. Chem. Phys. 1975, 65, 1739.

29. Tang, I. N.; Castleman, A. W. I. Chem. Phys. 1972, 57. $3638 ; 1974,60,3981$.

30. Meisels, G. G.; Sroka, G. J.; Mitchum, R. K. J. Am. Chem. Soc. 1974, 96, 5045. Meisels, G. G.; Mitchum, R. K.; Freeman, J. P. J. Phys. Chem. 1976, 80, 2845.

31. Meot-Ner, M.; Sieck, L. W.; Ausloos, P. J. Am. Chem. Soc. 1981, 103, 5342.

32. Bohme, D. K.; Stone, J. A.; Mason, R. S.; Stradling, R. S. Jennings, K. R. Int. J. Mass Spectrom. Ion Phys. 1981, 37, 283.

33. Stone, J. A.; Splinter, D. A.; Kong, S. Y. Can. J. Chem. $1982,60,910$.

34. Hiraoka, K.; Morise, K.; Shoda, T. Int. J. Mass Spectrom. Ion Processes 1985, 67, 11.

35. Szulejko, G. E.; Fisher, J. J.; McMahon, T. B.; Wronka, J. Int. J. Mass Spectrom. Ion Processes 1988, 83, 147.

36. McIver, R. T. Rev. Sci. Instrum. 1970, 41, 555. Bowers, M. T.; Webb, H. M.; McIver, R. T. J. Am. Chem. Soc. 1971, 93, 4314.

37. Henderson, W. G., Taagepera, D.; Holtz, D.; McIver, R. T.; Beauchamp, J. L.; Taft, R. W. J. Am. Chem. Soc. 1972, 94, 4728.

38. Aue, D. H.; Bowers, M. T. In Gas Phase lon Chemistry. Vol. 2, Bowers, M. T., Ed.; Academic: New York, 1979.

39. Bartmess, J. E.; Mclver, R. T. Jr. In Gas Phase Ion Chemistry, Vol. 2; Bowers, M T., Ed.; Academic: New York, 1979.

40. Bartmess, J. E.; Scott, J. A.; McIver, R. T. J. Am. Chem. Soc. 1979, 101, 606.

41. Larson, J. W.; McMahon, T. B. J. Am. Chem. Soc. 1983, 105, 2944.

42. Dunkin, F. C.; Fehsenfeld, F. C.; Schmeltekopf, A. L.; Ferguson, E. E. J. Chem. Phys. 1968, 49, 1365.

43. Schiff, H. I.; Bohme, D. K. Int. J. Mass Spectrom. Ion Phys. 1975, 16, 167. Bohme, D. K.; Mackay, G. I.; Schiff, H. I. J. Chem. Phys. 1980, 73, 4976.

44. Adams, N. G.; Smith, D.; Viggiano, A. A.; Pauison, J. F.; Henchman, M. J. I. Chem. Phys. 1986, 84, 6728.

45. Keesee, R. G.; Castleman, A. W. J. Phys. Chem. Ref. Data 1986, 15, 1011.

46. Lau, Y. K.; Saluja, P. P. S.; Kebatle, P.; Alder, R. W. I. Am. Chem. Soc. 1978, 100, 7328 .

47. Fukuda, E. K.; McIver, R. T. J. Chem. Phys. 1982, 77, 4942.

48. Kebarle, P.; Chowdhury, S. Chem. Rev. 1987, 87, 513.

49. Lias, S. G. Liebman, J. F.; Levin, R. D. I. Phys. Chem. Ref. Data 1984, 13, 695. Lias, S. G.; Bartmess, J. E.; Liebman, J. L.; Holmes, J. L.; Levin, R. D.; Mallard, W. G. J. Phys. Chem. Ref. Data 1988, 17, Suppl. 1. 